\title{
Keeping in touch with Soviet colleagues
}

Miles Reid, Royal Society Visiting Fellow in the Department of Mathematics at Tokyo University and Fellow of Christ's College, Cambridge, writes an open letter to scientists interested in maintaining and improving contacts with their Soviet colleagues

THE growth of international scientific and cultural ties is potentially of enormous value in developing the spirit of cooperation and friendship between nations. I personally believe we scientists can make a contribution towards making this world a safer and a more decent place to live in. But it is also my opinion that Western scientists do not make full use of existing channels of communication, perhaps due to traditional western misinformation as to what is or is not feasible.

Invitations to the West. The majority of Western scientists are probably familiar with the frustrating fact that senior (non-party) Soviet scientists invited to Western conferences find it impossible to take up the invitation.

The first step for any Soviet citizen in obtaining a visa to travel abroad is to get a reference from the Party Committee of his place of work recommending the visit; there are several subsequent steps where hitches may occur, but I believe the first step to be the essential obstacle, since if the Partkom is prepared to give its backing the remaining problems may turn out to be soluble.

Now there is some reason to believe that this obstacle may be less serious for younger scientists. This optimistic view is suggested partly by analogy with the case of visits from the USSR to the countries of eastern Europe (a closer analogy than most people in the West will be aware of); and partly by speculation as to the nature of the decision-making procedure within the Partkom of universities and institutes.

I would thus like to urge that every possible opportunity be taken to invite the younger generation of Soviet scientists to meetings in the West or to Western universities. In my field of mathematics (algebraic geometry) there is certainly no shortage of excellent young scientists, and visits to the West by such people, even for short periods, should provide for an extremely stimulating flow of ideas and information in both directions.

I would like to suggest that as a matter of form every invitation to a senior scientist should contain a clause to the effect that if the person invited feels unable to take up the invitation, he suggests the name of a junior colleague or research pupil who could be interested in coming in his stead. Of course, one does not necessarily expect that a research student of a particular scientist would be able to do more than give a token representation, but his presence will allow a flow of ideas, and will do something towards correcting the balance in the make-up of Soviet delegations.

As far as I am aware almost any young Soviet scientist would jump at the opportunity of travelling to the

'It seems to be the case that Western organisers who have had repeated failures in attempts to invite Soviet colleagues sometimes get discouraged and give up trying.

This is obviously wrong on probabilistic grounds'

West, and be extremely keen to attempt the considerable task of applying for permission. There is probably a practical upper bound of about two months on the length of time a Russian scientist would be allowed out, and one should allow for some uncertainty in the time of arrival.

Contrary to what is commonly supposed in the West, there is no reason of principle why a Soviet citizen having obtained permission to travel abroad should not support himself on the issue of dollars he is entitled to under the currency regulations, although I am informed that university authorities may be very much more impressed by an invitation promising support and even a contribution towards travel expenses.

Even for a (non-party) scientist with an impeccable student and Komsomol background the probability of being allowed out is probably no greater than one-tenth, and it seems to be the case that Western organisers who have had repeated failures in attempts to invite Soviet colleagues sometimes get discouraged and give up trying. This is obviously wrong on probabilistic grounds, since if the probability of success is small one should clearly make more attempts rather than fewer. And if one draws a blank after taking reasonable measures over a period of several years (such as writing periodic supporting letters to individual mem- bers of the university or institute management urging the advantages to both Western and Soviet science to be gained by some particular visit), then one is in a stronger position to complain that the Soviet side is being uncooperative.

There is certainly no way in which invitations addressed to an individual scientist, or letters enquiring as to the best way of inviting either him or one of his students could compromise him or lead to retaliation from the authorities.

I regard suggestions sometimes made that we take a hard-line attitude and boycott delegates we regard as too 'official' as potentially extremely harmful and counterproductive. It is my firm conviction that success in this matter will be directly proportional to the amount of patient effort which we are willing to exert.

The copyright convention. In 1973 the Soviet Union signed the Geneva copyright convention, thus bringing to an end the tradition of publishing pirate translations of Western books and journals. The potentially damaging effect of this on Soviet mathematics doesn't seem to have been generally realised. Before the copyright convention any important textbook was published in an edition of 10,000 (say), ensuring that every college, university or technical school was able to obtain a copy for its library. Similarly important Western articles found their way into libraries across the country in the form of translations in Matematika. Since the convention the number of textbooks translated has dwindled to an insignificant trickle, and Matematika has ceased publication.

Important university or institute libraries get an issue of foreign currency with which they can buy a selection of the essential literature; but this may have the effect of reducing contact with Western scientific ideas down to the scientists at a few major centres. An important additional source of foreign journals costing nothing in dollars is the exchange of publications, and every attempt should be made to extend the existing exchanges. The use of the photocopying machines at the major Soviet libraries remains at present expensive and inconvenient.

Contact by mail. A visitor at a Russian scientific centre is constantly embarrassed by being pumped for information about what's going on in the West; and the plea for preprints, lecture notes and copies of letters is invariably repeated in any discussion. I am not necessarily implying that the Western scientific community has been 
mean in this respect in the past, but I'd like to emphasise the desirability of sending as much information as possible.

Although it is true that every item of news received from the West is circulated and discussed with great interest, it is also true that even within Moscow there are many different institutes at which scientists are employed, and there may not be very close contact between them; a fortiori this applies to provincial universities. Western scientists need only consider how frequently they make photocopies of preprints or letters for their own use or for passing on to a colleague or student to realise the inconvenience of being deprived of this facility; so it doesn't seem unreasonable to suggest sending a larger number of preprints to a Russian university than one would to the corresponding Western university.

It is perhaps quite striking the extent to which the average scientist depends for his general outlook on informal contact. Thus one might discuss in conversation the work in progress of some colleague and gain thereby an overall impression of some new field of research without having to wait for the precise results to appear as preprints or articles. For a while now I have been trying to apply this principle in written form to try to bridge the gap between Soviet mathematicians in my field and the West, writing with occasional news of new developments (sometimes of which I have only the sketchiest knowledge myself). A slight difficulty is that there are in principle and in practice restrictions on one's correspondents' replies (see below), and one sometimes has to content oneself with the abstract knowledge that the communication is well received, and somehow get over the psychological difficulty of corresponding with someone whose replies are infrequent.

This idea has a potentially invaluable application to an international gathering at which no Soviet delegate is present, and I would like to suggest that if maybe two or three of the participants write their impressions of a few of the most exciting new results, and send three or four copies to interested colleagues in the Soviet Union, then this will do something towards correcting the isolation of Soviet science.

This problem has a converse: Russian scientists also complain that it is very difficult for them to send round copies of their recent work; some of the controversy about Russians not getting fair recognition for their original work perhaps stems from this difficulty.

An article prepared for publication in a Soviet journal will be typed, with three or four carbon copies made, of which several have to be submitted. It would be useful to have some system whereby a Soviet author who so desires could send out a carbon copy of his typescript to be copied and distributed in the West. This could perhaps be done officially, for example in connection with the translation schemes, or unofficially by private arrangement; those of us who are in correspondence with Soviet scientists should at any rate offer to perform this function.

\section{'It would be useful}

to have some system whereby a Soviet author who so desires could send out a copy of his typescript

to be distributed in the West. This could perhaps be done officially, for example in connection with the translation schemes, or unofficially, by private arrangement'

There are in principle two legal restrictions on what can be sent out of the Soviet Union. Firstly, the State holds the copyright on anything written by one of its citizens. And secondly an archaic clause of the State Secrets act requires that before sending abroad any written item containing mathematical formulae the sender must obtain the explicit permission of a scientific establishment-which involves the completion of exhaustive formalities, and is usually only possible if the item is already cleared for publication. In practice, however, scientific manuscripts and short items containing formulae are sent abroad rather frequently, as shown for example by the fact that Soviet scientists review regularly for Western journals and translate for the AMS. In general I am impressed by the amount of material that has been permitted in recent years to pass through the mail in both directions, and I would like to interpret this as an indication of the genuine application of one of the clauses of the Helsinki agreement.

It could be argued that the postal regulations, which make it impracticable for papers submitted to Soviet journals to be sent to a reviewer outside the USSR, are partly responsible for the uneven quality of some of the papers appearing in the Soviet scientific press.

Visits to the Soviet Union. The possibilities are as follows: as a tourist; by formal invitation; under the international Cultural Exchanges.

- It is perfectly feasible to visit, say, Moscow or Leningrad as a tourist, and nowadays the tourist gets a very reasonable deal (travelling with a group may be very much cheaper, and the group activities are not compulsory). When applying for a visa one is required to name the Soviet citizens one intends to meet, but there can be no objection to a scientist who intends to get in touch with colleagues declaring only one name.

It is perhaps worth pointing out in connection with the forthcoming International Congress of Mathematicians that Leningrad is just one night on the train away from Helsinki, and is a town that has considerable attraction to the tourist.

- Soviet scientists may be very willing to attempt to get an invitation made out to a Western colleague to visit them for periods of up to two months. However, it is fair to say that this is not necessarily straightforward. Certainly any Western scientist interested in this possibility should in the first instance write well in advance to a Soviet colleague with whom he has good scientific relations to discuss tactics.

- There are cultural exchanges in operation between the Soviet Union and every Western country. They take place both at the level of visiting fellowships (organised through the Academy of Sciences) and visiting studentships (through the Ministry of Higher Education), and represent almost the only practical possibility for a Western scientist to spend a long period (six months or a year) in contact with a Soviet scientific centre.

I would strongly recommend the latter to any Western research student of recent $\mathrm{PhD}$ who is interested in some aspect of Soviet science, is willing to learn Russian, and is prepared to face the difficulties as well as the varied delights of Soviet life. Copies of my report to the British Council containing some of the fruits of my two years' experience in the USSR will be available on request. The very least that Western universities can do to encourage the use of these exchanges is to display the advertising matter relating to them.

In conclusion I would remark that there are many countries in the world where the working conditions of scientists, and the ways in which contacts with the world scientific community can be improved, are subjects which certainly deserve further study. But it seems fair to say that the Soviet Union, the People's Republic of China and Czechoslovakia stand out as the three major countries of the world whose minimal cooperation in maintaining scientific contact amounts to a deliberate affront to the world academic community on the part of their governments. 